\title{
Study on Shunt Active Power Filter Control Strategies of Three-phase Grid-connected Photovoltaic Systems
}

\author{
Zoubir Chelli, Abdelaziz Lakehal ${ }^{2 *}$, Tarek Khoualdia², Yacine Djeghader ${ }^{1}$ \\ Department of Electrical Engineering, Faculty of Science and Technology, Mohamed-Cherif Messaadia University, \\ P.O. Box 1553, 41000 Souk Ahras, Algeria \\ 2 Department of Mechanical Engineering, Faculty of Science and Technology, Mohamed-Cherif Messaadia University, \\ P.O. Box 1553, 41000 Souk Ahras, Algeria \\ * Corresponding author, e-mail: lakehal21@yahoo.fr
}

Received: 15 March 2019, Accepted: 23 June 2019, Published online: 04 August 2019

\begin{abstract}
This paper deals with the improvement of the energy quality using shunt active power filter. The three-phase grid-connected photovoltaic generator consists in solar panels, a three-phase voltage inverter connected to the grid and a nonlinear load constituted by a diode rectifier bridge supplying a resistive load in series with an inductor. In so doing, three main challenges arise from the application context. First, the harmonic currents and the reactive power must be compensated. The second challenge is the injection of active solar energy into the grid. Third, Maximum Power Point Tracking (MPPT) must be found. This paper proposes a method addressing those challenges. For the first and the second one, direct current and power controls is used. For the third challenge, an algorithm is proposed which take in account the electrical variables and the variation of the solar irradiation. Simulation results of the proposed method are shown. The method is illustrated with two different strategies: Hysteresis Control and Direct Power Control (DPC) for a variable load. Obtained results are presented and compared in this paper to confirm the robustness and the superiority of DPC strategy compared to Hysteresis Control strategy. In the same context, the simulation carried out in this article shows promising results with THD approximates $1.33 \%$.
\end{abstract}

Keywords

energy quality, photovoltaic system, MPPT, Hysteresis Control, Direct Power Control

\section{Introduction}

Searching for the best compromise between economic, electrical and technological imperatives has always been the primary aim of the electrical engineer. Most electrical operation problems in grid-connected PV system are current harmonics, the grid distortions and disturbances which are caused due to rapid variations in the PV power [1]. Maximum Power Point Tracking (MPPT) is the most used solution to resolve the problems, specific to the intermittent and nonlinear of PV sources. MPPT algorithms have to be robust, stable, and fast. MPPT algorithms should be able to react in substantive ways to a large power range and changes in temperature and solar irradiation [2]. MPPT is obtaining the power from the PV arrays by multiplying the voltage and current of PV arrays and comparing it with previous measured power [3]. The shunt active power filter of three-phase grid-connected photovoltaic systems is expected to do the following controls:
- Reducing Total Harmonic Distortion (THD),

- Fast and adaptive regulation of voltage,

- Active power delivered,

- Maintaining the power factor,

- The output frequency to be the same as that of the grid and the MPPT.

The IEEE 519 standard recommends a THD of less than or equal to $5 \%$. Aissa et al. [4] through the use of an active filter controlled by a conventional DPC, found a THD equal to $1.77 \%$, and a THD equal to $1.35 \%$ for the predictive DPC. In other contribution and in the field of renewable energy, Senguttuvan and Vijayakumar [5] have used a Second Order Generalized Integrator (SOGI) for two cases:

1. under the load current changing and

2. under voltage and frequency variations. 
The results found shows that the THD $\%$ equal to $1.95 \%$ for the first case and $1.93 \%$ for the second case. Improving and finding a best value for THD remains a key goal for improving energy quality, something we will seek to achieve in this work with two different strategies: Hysteresis Control and Direct Power Control (DPC) for a variable load.

Control strategies of MPPT have been discussed in literatures. In the objective to improve the quality of power in a grid connected to the renewable energy system, Suja and Raglend [6] have been proposed a Neuro Fuzzy artificial inference system controller, and Unified Power Quality Conditioner (UPQC). Analyzing the incidence of the power quality at the common coupling point in a grid connected renewable energy systems is the main contribution. Xu et al. [7] by using SVM method and DPC technique, they have proposed a new control technique in the objective is to generate the converter switching signal. The results obtained in this work is summarized in providing a line current very close to sine waveforms ( $\mathrm{TDH}<2 \%$ ), and good DC bus voltage regulation. An optimization-based MPPT algorithm is developed in [8]. It is based on a Particle Swarm Optimization (PSO) techniques and damps out oscillations in the dc-link voltage.

However, the active filter is an effective way to overcome harmonic pollution [9]. Through this contribution we will seek to study a system consisting of a photovoltaic generator and a parallel active filter. The role of the first element is the injection of the active power and the second is the elimination of the disturbances which can present it on the grid [10]. Phase Angle Control strategy and Hysteresis Current Control strategy are studied [11]. The second strategy showed by far the best results. In this paper two different control strategies are taken up for implementation, which are Hysteresis Control and Direct Power Control strategy.

The remaining of this paper is organized as follows:

- Section 2 is dedicated to present the studied the three-phase grid-connected photovoltaic system.

- Section 3 is dedicated to describe Hysteresis Control strategy and Direct Power Control strategy.

- Simulation results of the proposed control strategies are provided in Section 4.

- Finally, conclusions are presented at Section 5.

\section{Proposed system structure}

The proposed system in this work composed of a photovoltaic solar generator connected to the DC bus of a threephase inverter. It is also coupled in parallel to the grid via an inductor. This grid supplies a nonlinear load consisting of a series load $P D_{3}$ rectifier with an inductance (Fig. 1).

The BP MSX-150 photovoltaic module is adopted for modeling and simulation. This module is composed of (72) multi-crystalline silicon solar cells and provides a maximum power rating of $150 \mathrm{~W}$. Table 1 gives the characteristics of this photovoltaic panel.

$$
I=I S c \cdot\left[1-\left(\exp \left[\frac{V-V o c \cdot \mathrm{NS}+1 R s \cdot \mathrm{NS}}{V t h}\right]\right)\right]
$$

Open Circuit Voltage (Voc) and Short Circuit Current (ISC) are obtained by Eqs. (2) and (3) respectively:

$V o c=V o c(\mathrm{STC})+C_{3} \cdot\left(T c-T c(\mathrm{STC})+V t h \ln \left[\frac{G a}{G a(\mathrm{STC})}\right]\right)$

$I s c=C_{1} \cdot G a\left[1+(T c-T c(\mathrm{STC})) \cdot 5 \cdot 10^{-4}\right]$

with

$C_{1}=(\operatorname{Isc}(\mathrm{STC})) / G a(\mathrm{STC})$.

The coefficient $\mathrm{C}_{3}$ represents the voltage correction factor of the open circuit as a function of the temperature. The typical value of this factor is $-2.310^{-3} \mathrm{~V} /{ }^{\circ} \mathrm{C}$. Cells temperature $(T c)$ depends on the solar irradiation $G a$ and the ambient temperature $T a$.

$T c$ : Absolute temperature of the junction operation $\left(\mathrm{K}^{\circ}\right)$, and $V t h$ : the thermal stress.

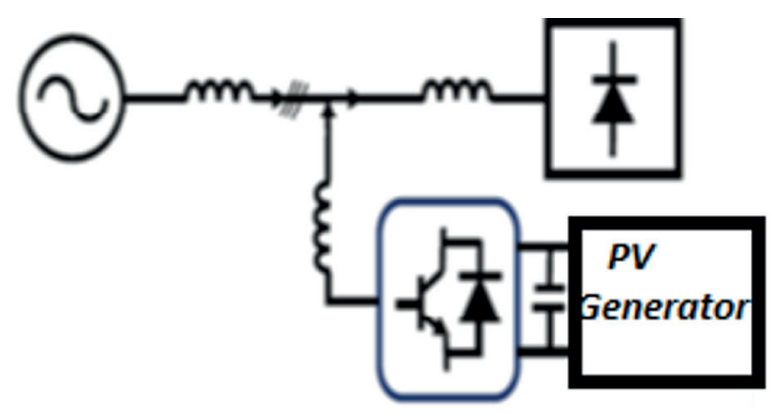

Fig. 1 Proposed system, which based on grid-connected PV and three-phase voltage inverter

Table 1 PV generator characteristics

\begin{tabular}{lc}
\hline Physical characteristics & BP MSX-150 \\
\hline Number of cells in series (NS) & $\mathrm{NS}=72$ \\
Number of cells in parallel (NP) & $\mathrm{NP}=1$ \\
Electrical characteristics (STC) & $G a=1000 \mathrm{~W} / \mathrm{m}^{2} .25^{\circ} \mathrm{C}$. AM1.5 \\
Maximum power $\left(P_{\max }\right)$ & $150 \mathrm{~W}$ \\
Maximum point voltage $($ Vmpp $)$ & $34.28 \mathrm{~V}$ \\
Current at maximum point $($ Impp $)$ & $4.375 \mathrm{~A}$ \\
Open Circuit Voltage $(V o c)$ & $43.5 \mathrm{~V}$ \\
Short Circuit Current $(I s c)$ & $4.74 \mathrm{~A}$ \\
\hline
\end{tabular}


Matlab Simulink is used to build the equivalent model of the PV generator. Equations (1), (2) and (3) are used to subdivide the PV generator into blocks representing the different elements of its equivalent model (Fig. 2). Simulation parameters of the shunt active power filter are shown in Table 2. The temperature $(T)$ of the cell, the irradiation ( $G a$ ) and the number of the serial photovoltaic cells (NS) are accessible as external variables and can be modified during the simulation process. This aids in observing and evaluating the reaction of the system to sudden changes in operating conditions, such as the sunshine variations.

\section{The used control strategies}

\subsection{Control algorithm for MPPT}

The proposed MPPT algorithm is shown in Fig. 3. With $i_{d}(k)$ is the three-phase source current representation in the synchronous reference frame $d-q, \Delta i_{G}(k)$ represents the power variation caused by the change in solar irradiation.

$\Delta i_{G}(k)$ is obtained by:

$\Delta i_{G}=T_{e} \cdot \varepsilon \cdot k_{i}=T_{e} \cdot k_{i}\left(V_{d c r e f}(k-1)-V_{d c}(k)\right)$.

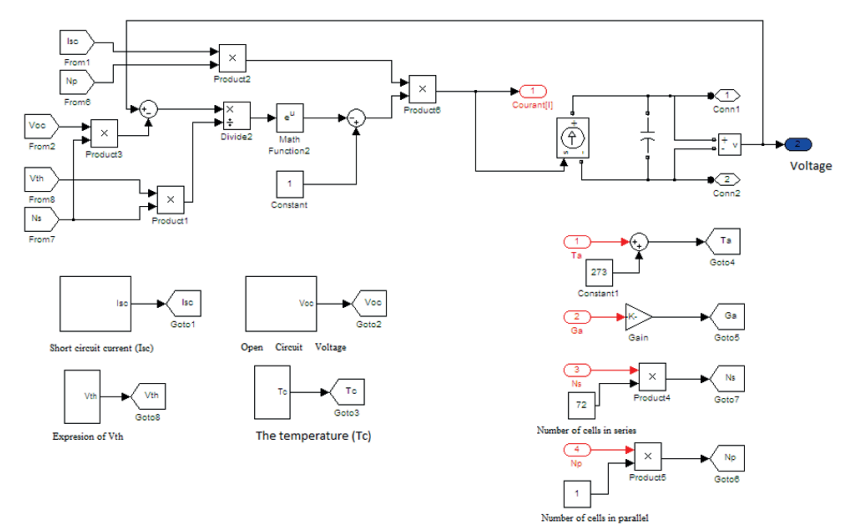

Fig. 2 Modeling of PVG under Matlab

Table 2 Shunt active power filter parameters

\begin{tabular}{|c|c|c|}
\hline System & Parameters & Values \\
\hline Power source & $\begin{array}{l}\text { - The effective tension } \\
\text { - Frequency } \\
\text { - The internal resistance } \\
\text { - The internal inductance }\end{array}$ & $\begin{array}{c}V s=100 \mathrm{~V} \\
F=50 \mathrm{HZ} \\
R s=0.1 \Omega \\
L s=0.1 \mathrm{mH}\end{array}$ \\
\hline \multirow{2}{*}{$\begin{array}{l}\text { Nonlinear } \\
\text { load }\end{array}$} & $\begin{array}{l}\text { Bridge } P D_{3} \text { three-phase rectifier } \\
\text { with } R-L \text { load }\end{array}$ & $\begin{array}{c}R L_{1}=6.1 \Omega \\
R L_{2}=10 \Omega \\
L=20 \mathrm{mH}\end{array}$ \\
\hline & $\begin{array}{l}\text { Inductance filtering at the input of } \\
\text { the bridge } P_{3}\end{array}$ & $\begin{array}{c}R c=0.01 \Omega \\
L c=0.57 \mathrm{mH}\end{array}$ \\
\hline $\begin{array}{l}\text { Shunt active } \\
\text { power filter }\end{array}$ & $\begin{array}{l}\text { - } \text { Storage capacity } \\
\text { - Coupling inductance } \\
\text { - Hysteresis band }\end{array}$ & $\begin{array}{c}C_{d c}=2200 \mu \mathrm{F} \\
L f=2 \mathrm{mH} \\
\mathrm{HB}=0.2 \mathrm{~A}\end{array}$ \\
\hline
\end{tabular}

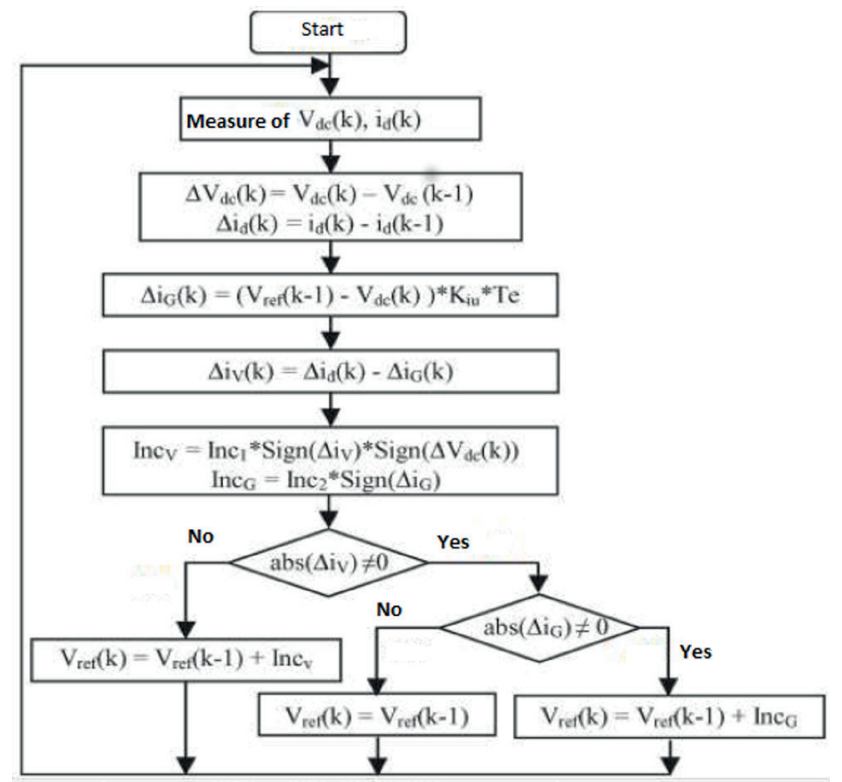

Fig. 3 Flowchart of the proposed algorithm

The discretized writing of the current on the axis $d$ lasts a sampling period $T_{e}$ in the situation of variation of the solar irradiation is expressed as:

$\Delta i_{d}(k)=\Delta i_{G}(k)+\Delta i_{\vartheta}(k)$.

$\Delta i_{9}(k)$ represents the variation of the current on the axis component generated by the perturbation increments of the MPPT algorithm $\left(I_{n c v}\right)$. The first $I_{n c v}$ is used when the output voltage of the panel is removed from the voltage of the MPP, and the second $I_{n c G}$ in the presence of a variation of the solar irradiation.

\subsection{Hysteresis Control strategy}

Hysteresis Control, is a nonlinear control that uses the error existing between the reference current $I_{\text {fref }}$ and the current produced by the inverter $I_{f}$. The error is compared to a hysteresis band. A control command is sent in order to stay inside the band in the case when the error reaches the lower or higher band. This technique has advantages and disadvantages. The advantages are:

- the simplicity of implementation,

- the robustness and

- its good dynamics.

Some disadvantages are:

- The switching frequency is not fixed; it depends on the hysteresis band and of the current derivative.

- The command is applied separately on all three phases.

- The structure electro-technical system imposes at every moment that the sum of the three currents is zero. 
- The result obtained on one current is not independent of the other two phases. Thus, the enslaved current cannot respect the limits imposed by the band of hysteresis [9].

\subsection{Direct Power Control strategy}

The principle of DPC has been proposed in [12] and developed later in many applications. The objective is to eliminate the modulation block and internal loops by replacing them with a switchboard whose inputs are the errors between the reference values and the measurements. With the DPC there is no current control loop or PWM modulation element, because the switching states of the inverter, for each sampling period, are selected from a switching table, based on the instantaneous error between reference values and those measured or estimated active and reactive powers, and the angular position of the source voltage vector. Generally, with this control strategy, the DC bus voltage is regulated for active power control and operation with a factor of unit power is obtained by imposing the reactive power at a zero value [13].

Selecting a control vector according to a switching table is the principal of DPC. The switching table is based on the digitized error, $S p$ and $S q$ which are limited by a two-level hysteresis band, as well as on the angular position of the voltage at the point of connection of the load to the PCC networks. The plane $(\alpha-\beta)$ is divided into twelve sectors to determine the work area. DPC is illustrated in Fig. 4.

Equations (6) and (7) are obtained by the representation of the powers in the rotating reference $(d, q)$ :

$$
\begin{aligned}
& p_{s}=v_{s d} \cdot i_{s d}+v_{s q} \cdot i_{s q} \\
& q_{s}=v_{s q} \cdot i_{s d}-v_{s d} \cdot i_{s q} .
\end{aligned}
$$

The optimal state of switching of the inverter is chosen at each switching state according to the switching of the digital signals $S p, S q$ and sector that is to say, that the

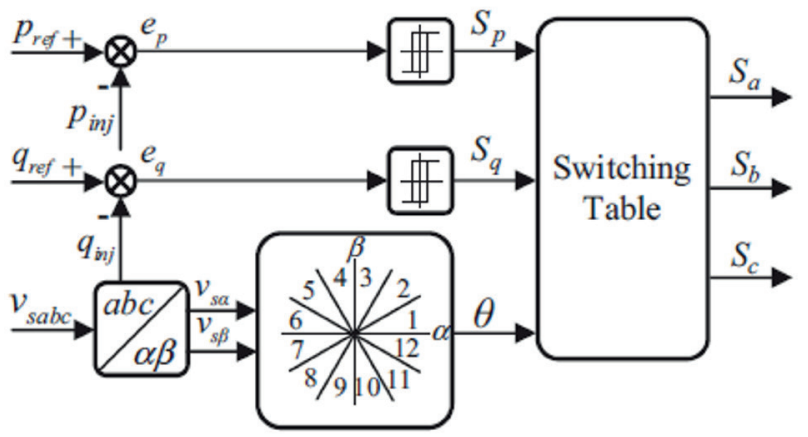

Fig. 4 Illustration of the DPC choice is made so that the error of the instantaneous active and reactive power can be restricted in a desired band. In the two-phase plane $(\alpha, \beta)$, considering $\vec{v}_{f}$ the vector corresponding to the voltages of the inverter, the eight possible cases of the vector $\vec{v}_{f}$ are given in Table 3 .

To select the appropriate voltage vector, the criteria in Table 4 must be met.

If the power error is $e_{q} \geq 0 p \geq 0$, the voltage vectors that must be selected are voltage vectors that act as a capacitive effect and a power source as $v_{1}$ or $v_{6}$. If $e_{q} \geq 0$ and $e_{p}<0$, the voltage vectors that must be selected are voltage vectors that act as a capacitive effect and a load like $v_{0}, v_{7}$ or $v_{5}$. Instant reactive power control has a higher priority than

\begin{tabular}{|c|c|c|c|c|c|c|}
\hline Vector & $S_{a 1}$ & $S_{b 1}$ & $S_{c 1}$ & $\mathrm{~V}_{\mathrm{fa}}$ & $v_{f b}$ & $v_{f c}$ \\
\hline$v_{0}$ & 0 & 0 & 0 & 0 & 0 & 0 \\
\hline$v_{1}$ & 1 & 0 & 0 & $2 V_{d c}$ & $-V_{d c} / 3$ & $-V_{d c} / 3$ \\
\hline$v_{2}$ & 1 & 1 & 0 & $V_{d c}$ & $V_{d c}$ & $-2 V_{d d}$ \\
\hline$v_{3}$ & 0 & 1 & 0 & & $2 V_{d c} / 3$ & \\
\hline$v_{4}$ & 0 & 1 & 1 & $-2 V_{d c}$ & $V_{d c} / 3$ & $V_{d c}$ \\
\hline$v_{5}$ & 0 & 0 & 1 & & $-V_{d c}$ & $2 V_{d c}$ \\
\hline$v_{6}$ & 1 & 0 & 1 & $V_{d c} / 3$ & $-2 V_{d c}$ & $2 V_{d c}$ \\
\hline$v_{7}$ & 1 & 1 & 1 & 0 & 0 & 0 \\
\hline
\end{tabular}

Table 3 Voltage generated by the inverter

\begin{tabular}{|c|c|c|c|}
\hline $\begin{array}{l}\text { Power } \\
\text { errors }\end{array}$ & $\begin{array}{l}\text { Criteria } \\
\text { for } \\
\text { selecting } \\
\text { voltage } \\
\text { vectors }\end{array}$ & Application examples & Power errors \\
\hline \multirow{2}{*}{$e_{q} \geq 0$} & $e_{p} \geq 0$ & $\begin{array}{l}\text { Voltage vectors that act } \\
\text { as a capacitive effect and } \\
\text { a source of power }\end{array}$ & Choice $v_{1}$ or $v_{6}$ \\
\hline & $e_{p}<0$ & $\begin{array}{c}\text { Voltage vectors that act } \\
\text { as a capacitive effect } \\
\text { and a load }\end{array}$ & $\begin{array}{c}\text { Choice } v_{0}, v_{7} \\
\text { or } v_{5}\end{array}$ \\
\hline \multirow{2}{*}{$e_{q}<0$} & $e_{p} \geq 0$ & $\begin{array}{c}\text { Voltage vectors that act } \\
\text { as a capacitive effect and } \\
\text { a source of power }\end{array}$ & Choice $v_{2}$ \\
\hline & $e_{p}<0$ & $\begin{array}{c}\text { Voltage vectors that act } \\
\text { as a capacitive effect } \\
\text { and a load }\end{array}$ & $\begin{array}{c}\text { Choice } v_{0}, v_{7}, \\
v_{3} \text { or } v_{4}\end{array}$ \\
\hline
\end{tabular}

Table 4 Selected voltage vectors for AC Power 
active power control. The same reasoning is used for the selection of the voltage vectors for the other sectors, which gives the switching table presented by the Table 5 .

\section{Simulation results and discussion}

The photovoltaic compensation system consists of a PVG, a chopper in booster mode and an active shunt filter that connects to the grid. Nonlinear load is feeds by this grid. The proposed compensation system plays the role of a compensator reagent in the case of low solar irradiation, and plays the role of a shunt active filter with a real power injection to the grid produced by the photovoltaic conversion chain in the case of strong solar irradiation. The temperature and the solar irradiation are fixed at standard conditions (STC) $\left(G a=1000 \mathrm{~W} / \mathrm{m}^{2}, T a=25^{\circ} \mathrm{C}\right)$ and the global system is simulated with two types of control of the inverter (active filter), the Hysteresis Control and the DPC so as to operate the system as a source of energy (injection of mains power) and an active shunt filter (harmonic compensation and reactive power). Figs. 5 and 6 show the waveforms of the three-phase source current and the current consumed by the nonlinear load, and the active and reactive powers of the three-phase source before introducing the photovoltaic compensation system.

In the first case, where the system operates without SAPF; the load consumes an active power of $4 \mathrm{KW}$, the source currents are identical to those of the nonlinear load $\left(I_{s}=I_{l}=27.84 \mathrm{~A}\right)$ characterized by a spectrum containing only harmonics of odd order (not multiples of three) and a THDi $=23.29 \%$ (Fig. 7).

\subsection{System simulation with Hysteresis Control strategy for the SAPF}

- Variation of the nonlinear charge

A variation of the nonlinear charge is applied with a passage from $R L_{1}$ to $R L_{2}$ to studying the robustness of the control. Fig. 8 shows that at $t=0.25 \mathrm{~s}$ the load currents show a sharp increase as the source currents retain their sinusoidal shapes, and the source voltages show no disturbance. In addition, the DC bus
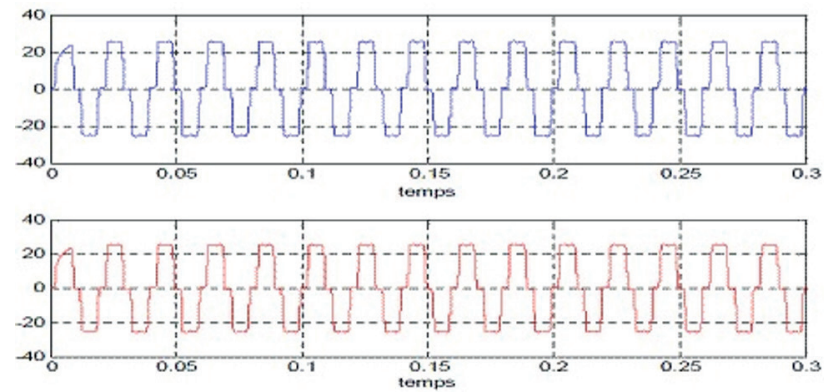

Fig. 5 Current waveforms before photovoltaic compensation

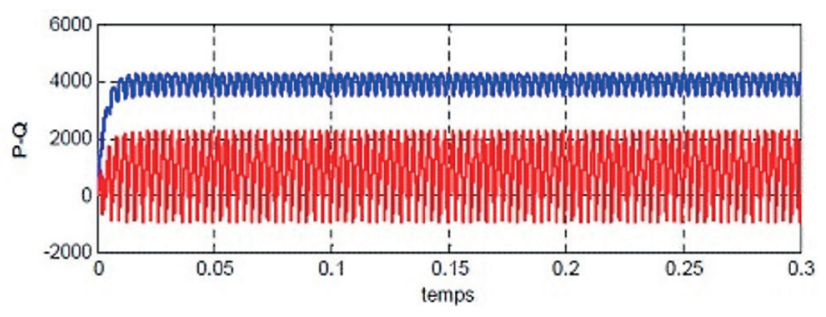

Fig. 6 Active and reactive power characteristic

voltage temporarily decreases and rejoins after a transient of $t=0.1 \mathrm{~s}$ its reference value (Fig. 9).

Fig. 10 shows the characteristics of the PVG during the load variations, after a transient of $t=0.1 \mathrm{~s}$, the voltage and the current tend towards these nominal values within a restricted margin and the duty cycle is greater than 0.5 , so the chopper always works as a generator voltage booster, to the $V_{d c r e f}$ DC bus reference voltage adaptation algorithm. The results of this load variation is a remarkable increasing in the active power at time $t=0.25 \mathrm{~s}$, whereas the reactive power remains unchangeable and equal to zero in the objective to ensure good compensation of the reagent (Fig. 11). In this case of load variation, the injected power by the PVG is the same for the corresponding grid of MPP of PVG (Fig. 12).

The Total Harmonic Distortion rate of the source current is improved and is worth THDi $=2.51 \%$ (Fig. 13 (a)) and the Total Harmonic Distortion rate of the source voltage becomes THDv $=3.55 \%$ (Fig. 13 (b)).

Table 5 DPC switching table

\begin{tabular}{ccccccccccccccc}
\hline$S p$ & $S q$ & $V_{1}$ & $V_{2}$ & $V_{3}$ & $V_{4}$ & $V_{5}$ & $V_{6}$ & $V_{7}$ & $V_{8}$ & $V_{9}$ & $V_{10}$ & $V_{11}$ & $V_{12}$ \\
\hline \multirow{2}{*}{1} & 0 & 110 & 110 & 010 & 010 & 011 & 011 & 001 & 001 & 101 & 101 & 100 & 100 \\
& 1 & 100 & 100 & 110 & 110 & 010 & 010 & 011 & 011 & 001 & 001 & 101 & 101 \\
& 0 & 010 & 011 & 011 & 001 & 001 & 101 & 101 & 100 & 100 & 110 & 110 & 010 \\
0 & 1 & 001 & 101 & 101 & 100 & 100 & 110 & 110 & 010 & 010 & 011 & 011 & 001 \\
\hline
\end{tabular}



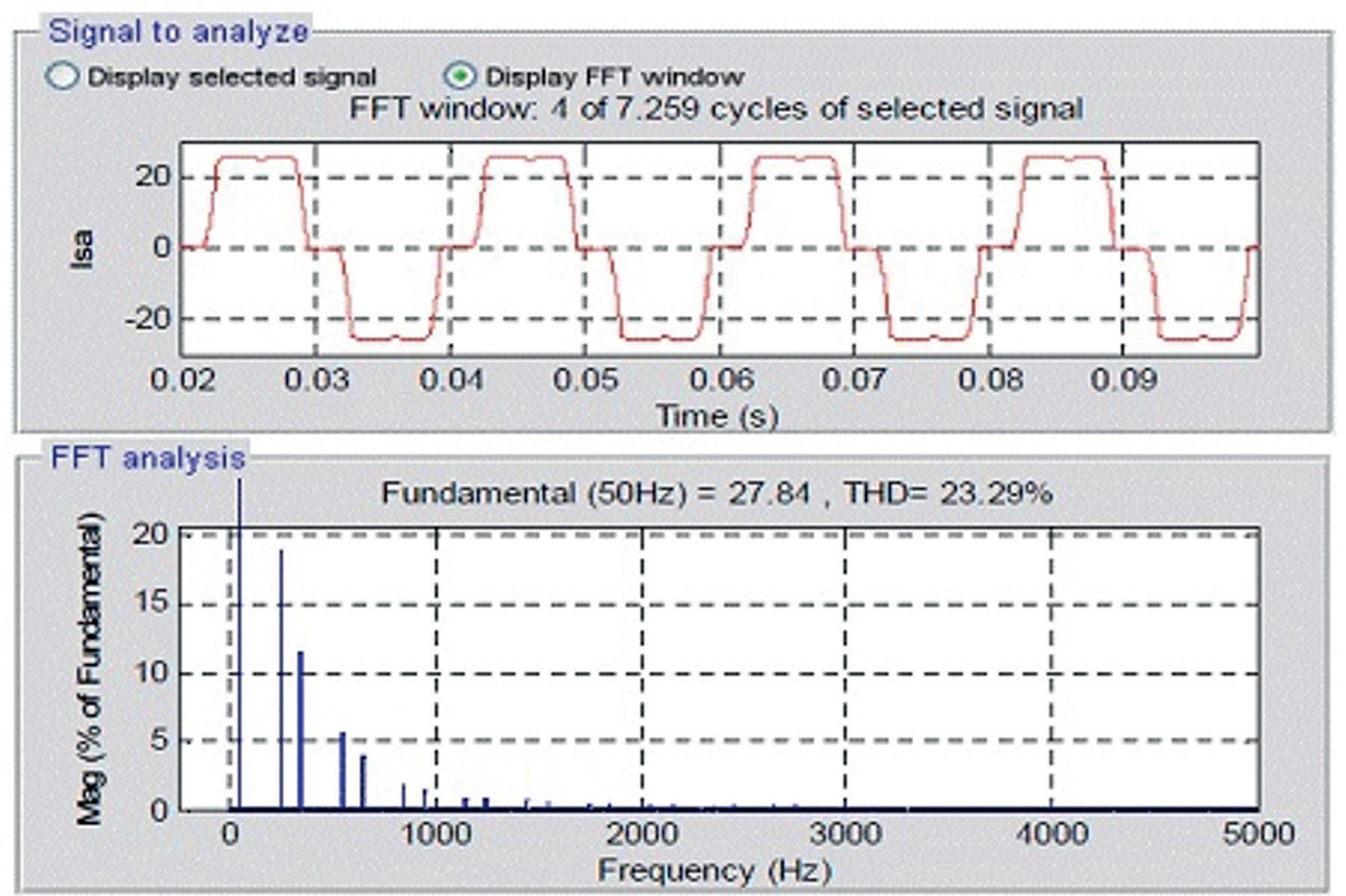

Fig. 7 Spectral analysis of the source current before commissioning of the SAPF
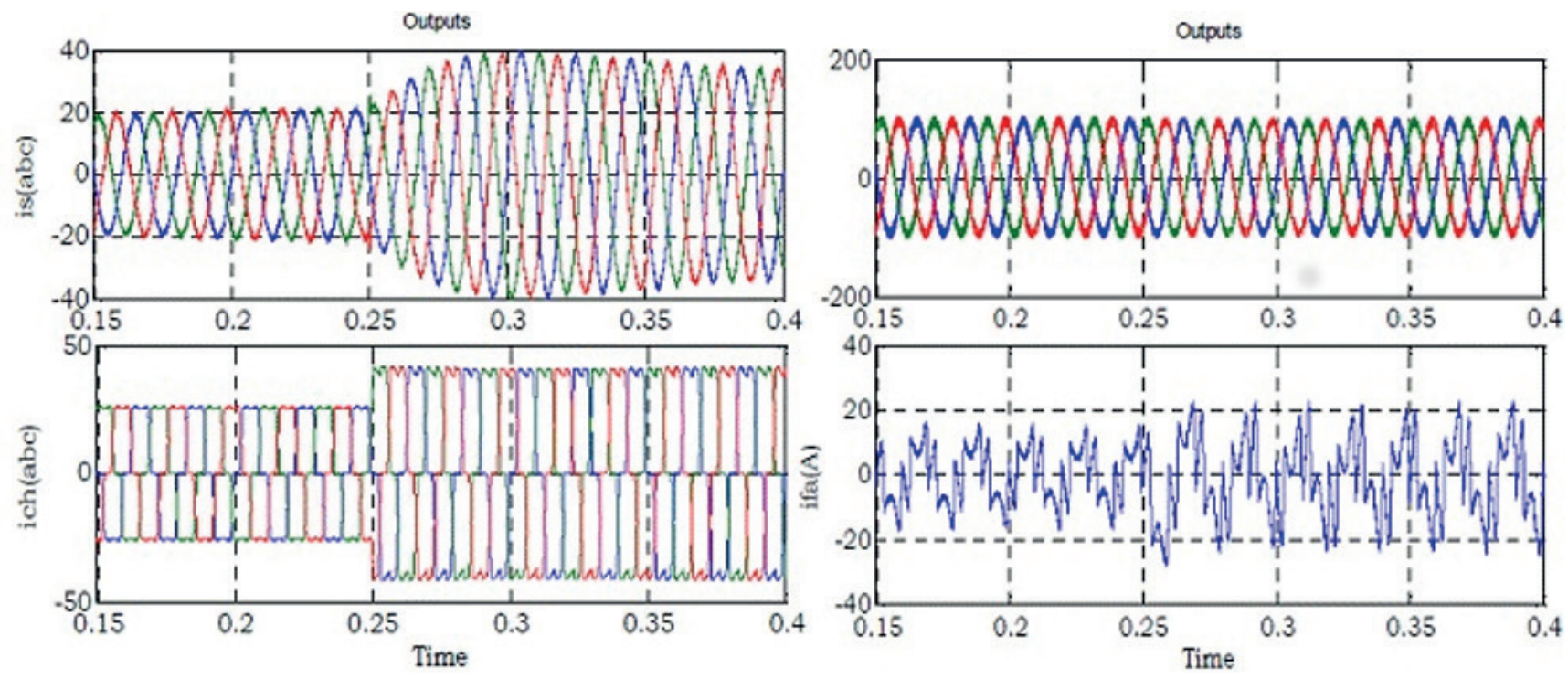

Fig. 8 Influence of load variation on the results of the simulation

- Simulation of the general system with variable solar irradiation

For this simulation it is necessary to apply a sudden variation $(G a=1000 \stackrel{0.2 s}{\rightarrow} 50 \rightarrow 1000)$, this variation causes a variation of current (Fig. 14).

Fig. 14 confirms that the current Ipv is considerably influenced by changing in the solar irradiation $G a$, whereas the voltage $V p v$ remains approximately constant.
Fig. 15 represents the waveforms of the current of the three-phase source and the load, when changing the solar irradiation.

Fig. 16 shows the waveforms of compensation current and voltage source during solar irradiation changing.

According to Figs. 15, 16 and during the changing of the solar irradiation, the current source presents a variation $\left[20 \mathrm{~A}\right.$ when $G a=1000 \mathrm{~W} / \mathrm{m}^{2}$ and $27 \mathrm{~A}$ when $\left.G a=50 \mathrm{~W} / \mathrm{m}^{2}\right]$, although that the form remains 


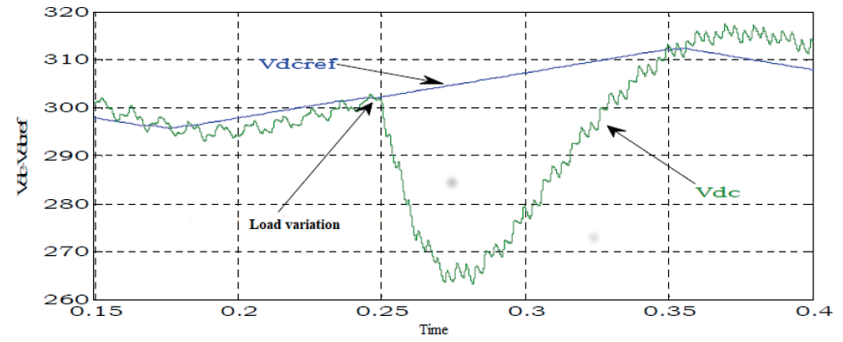

Fig. 9 DC bus voltage rate and its reference voltage
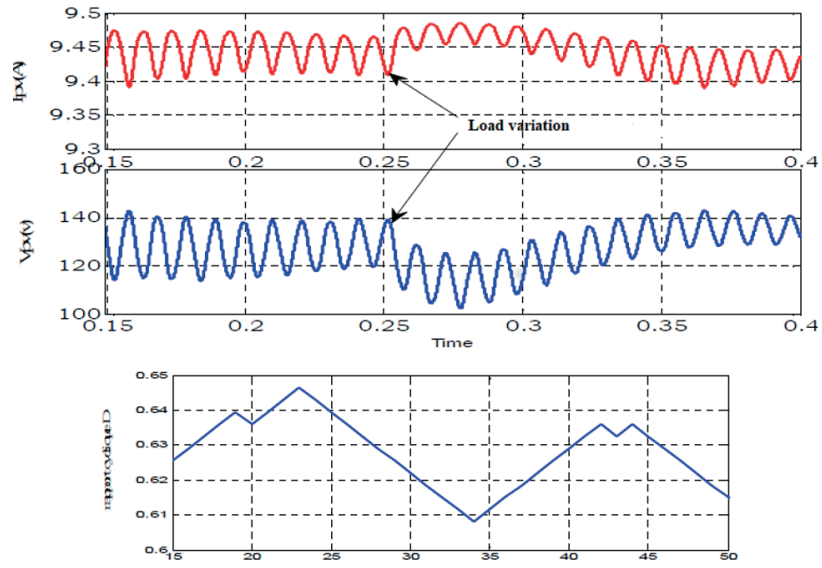

Fig. 10 Characteristic of the PVG during the variation of the nonlinear load

sinusoidal during this changing. This proves that we have an injection of active power.

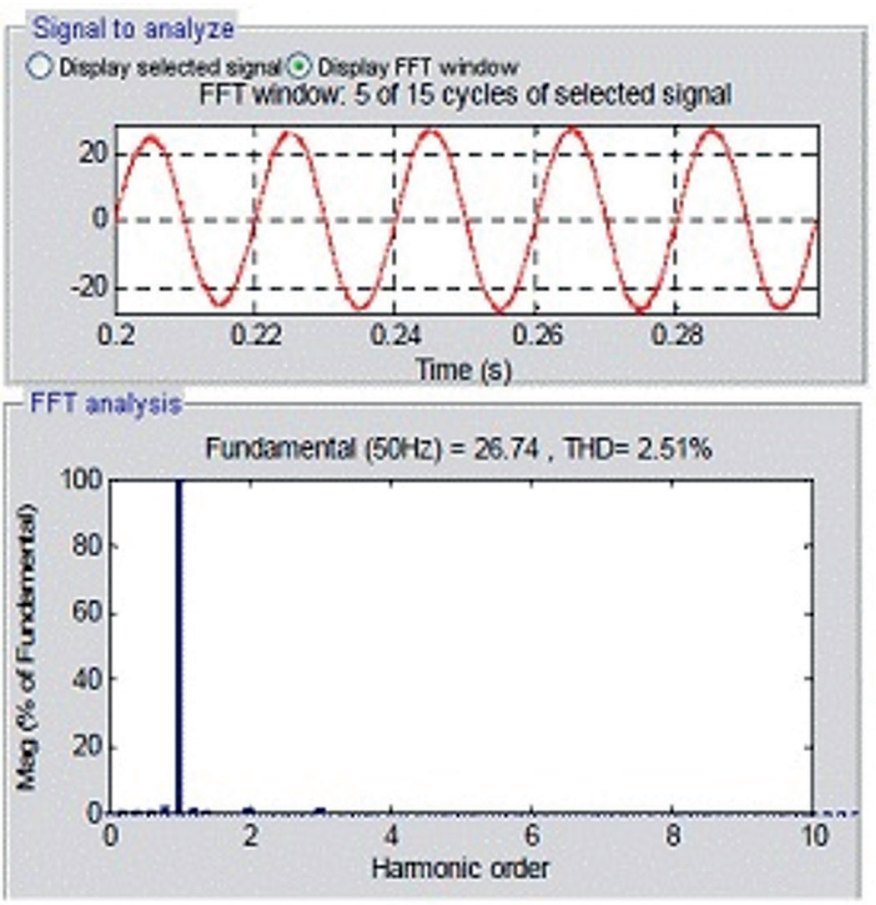

(a)

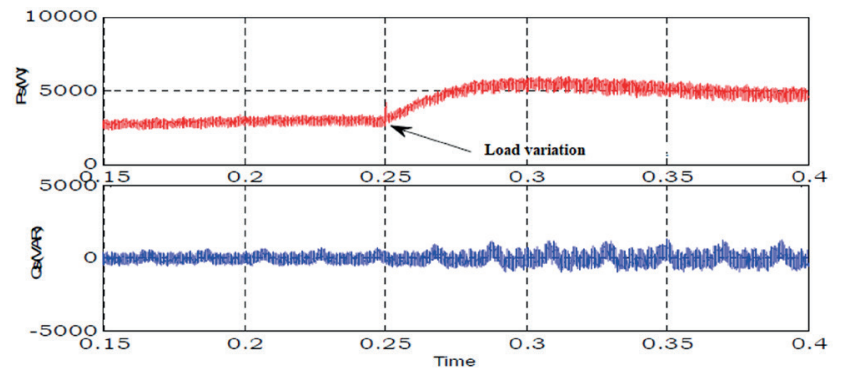

Fig. 11 Waveforms of instantaneous powers for a variation of the nonlinear load

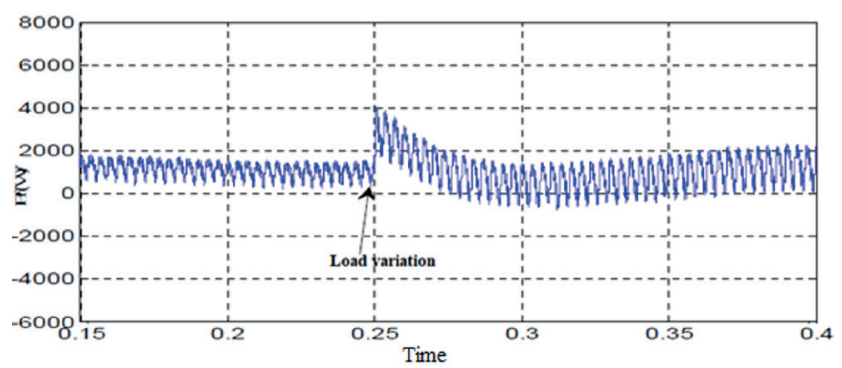

Fig. 12 The active power rate injected into the grid when the load varies

Fig. 17 illustrates the waveforms of the active and reactive powers during the changing of the solar irradiation. It is observed that the active power undergoes an increase at the time of irradiation by switching from 1000 to 50, which proves that the power injected by the PVG has decreased (1000 W- $50 \mathrm{~W}$ ) (Fig. 18),
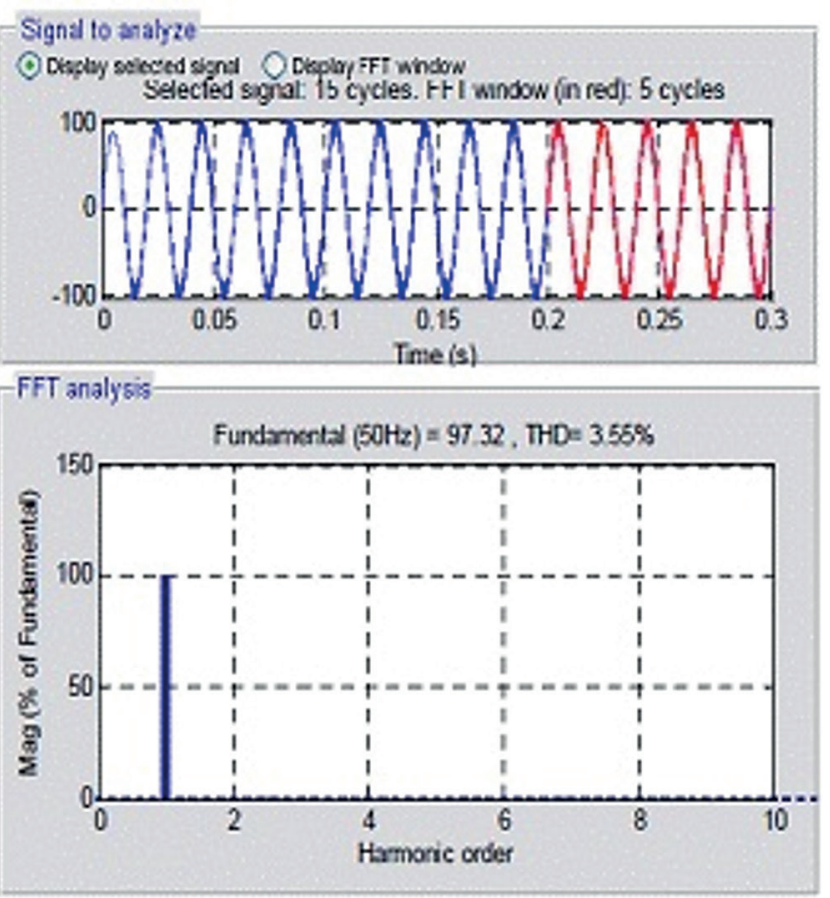

(b)

Fig. 13 Different spectra after SAPF commissioning: (a) source current, (b) source voltage 


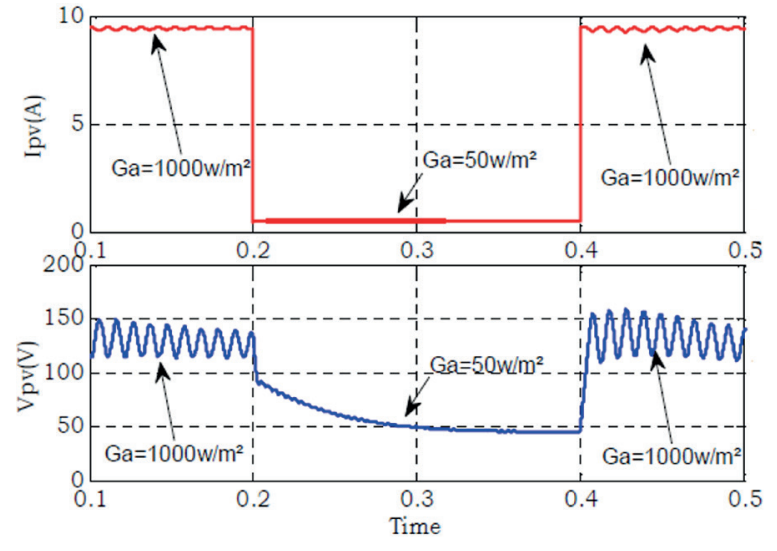

Fig. 14 Current and Voltage of GPV generator during irradiation changing

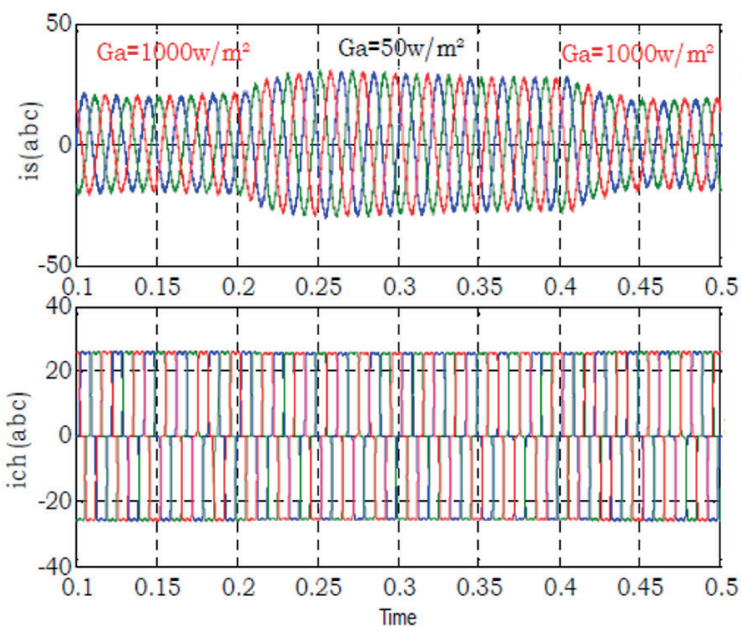

Fig. 15 Current of the three-phase source and the load waveforms when changing the solar irradiation

whereas the energy reactive continues to vary around zero. Regarding the DC bus voltage, it follows its reference during irradiation changing, to ensure a good compensation of the reactive power (Fig. 19).

THD is improved, THDi $=3.32 \%$ (Fig. 20) and $\mathrm{THDv}=1.5 \%$ (Fig. 21). According to these observations; despite the changing of the solar irradiation and due to the DC bus reference voltage adaptation algorithm, the reactive power compensation remains stable.

\subsection{DPC command for the SAPF}

- Variation of the nonlinear charge

One of the disadvantages of the Hysteresis Control strategy is the variation of the hysteresis band. In other words, when this band decreases, the switch does not support the high switching frequencies. To alleviate this constraint, the DPC method is proposed.

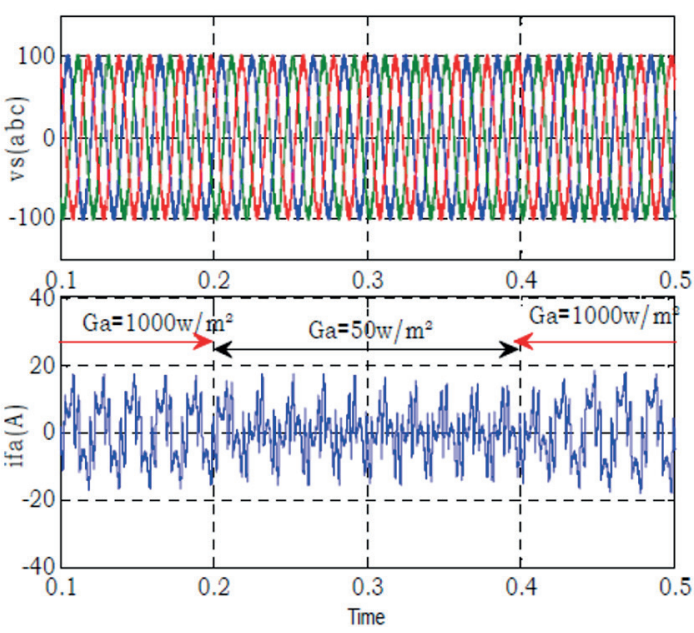

Fig. 16 The waveforms of compensation current and voltage source during solar irradiation changing.

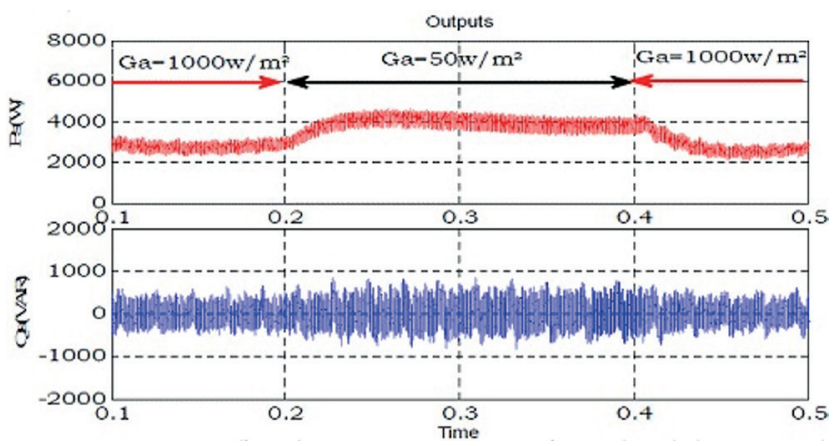

Fig. 17 The waveforms of active and reactive powers during solar irradiation changing.

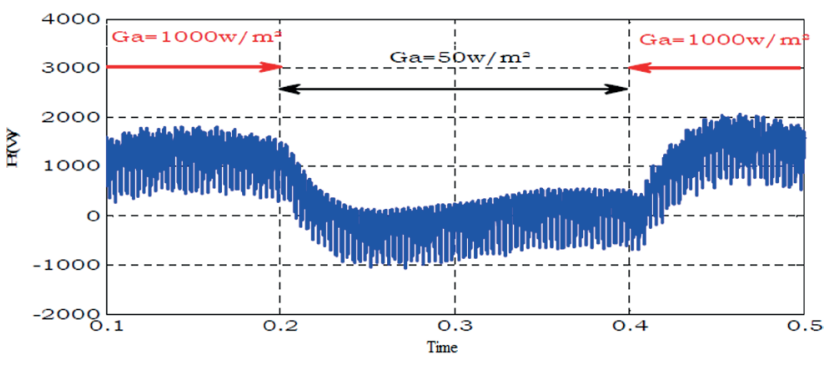

Fig. 18 Active power injected into the grid during solar irradiation changing

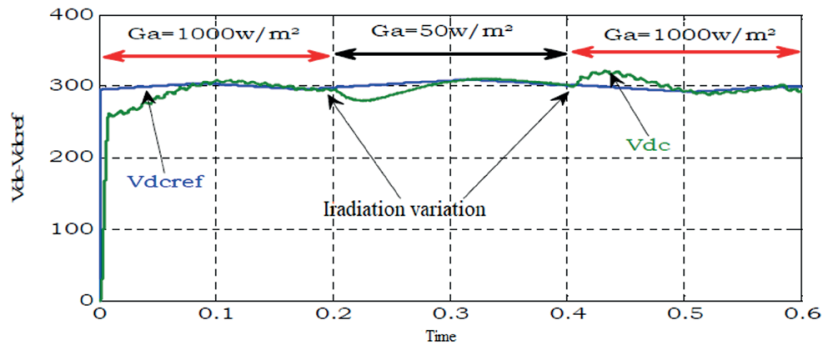

Fig. 19 The waveforms of the DC bus voltage and its reference voltage during solar irradiation changing. 


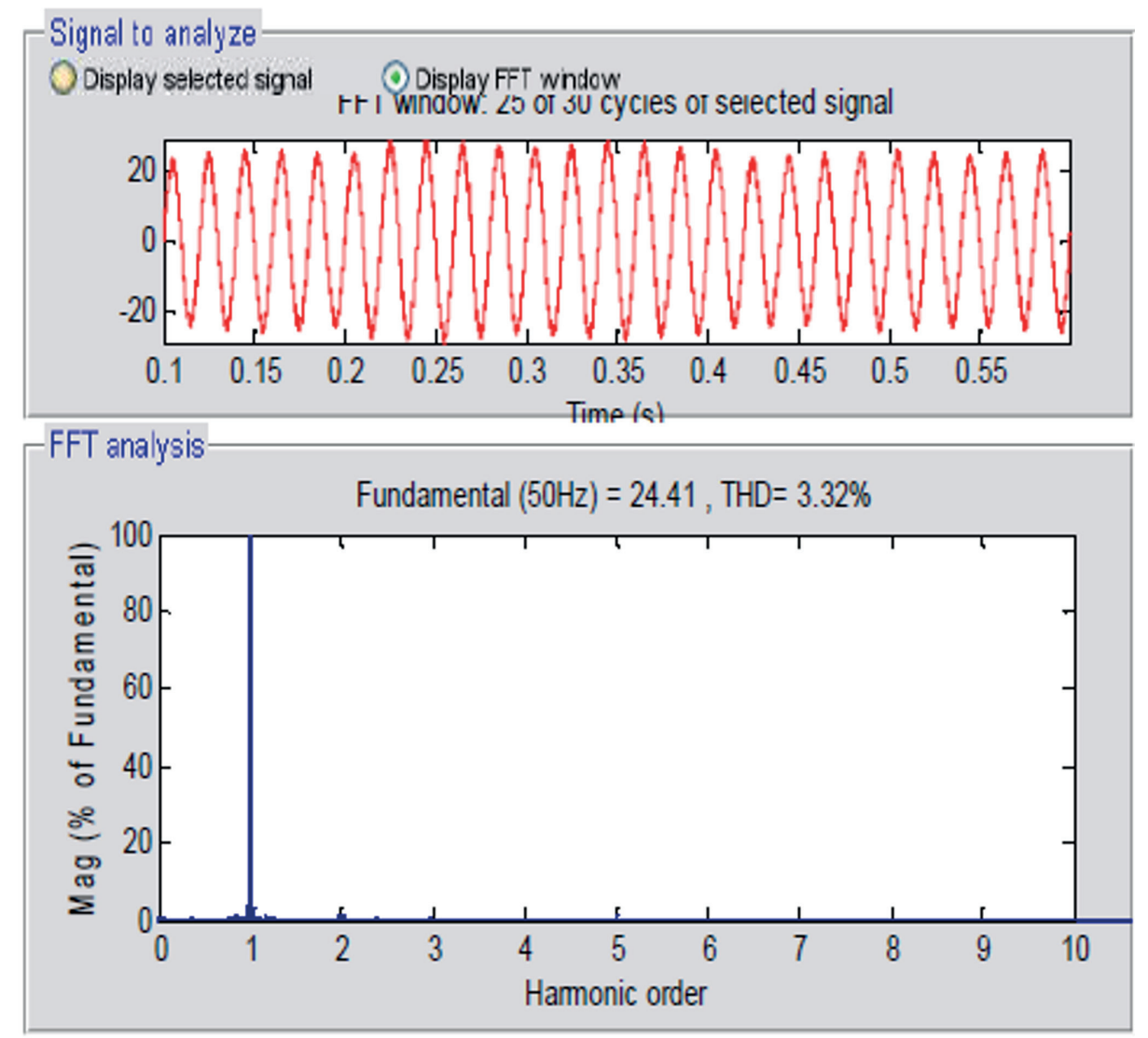

Fig. 20 Current source and its spectrum after installing SAPF
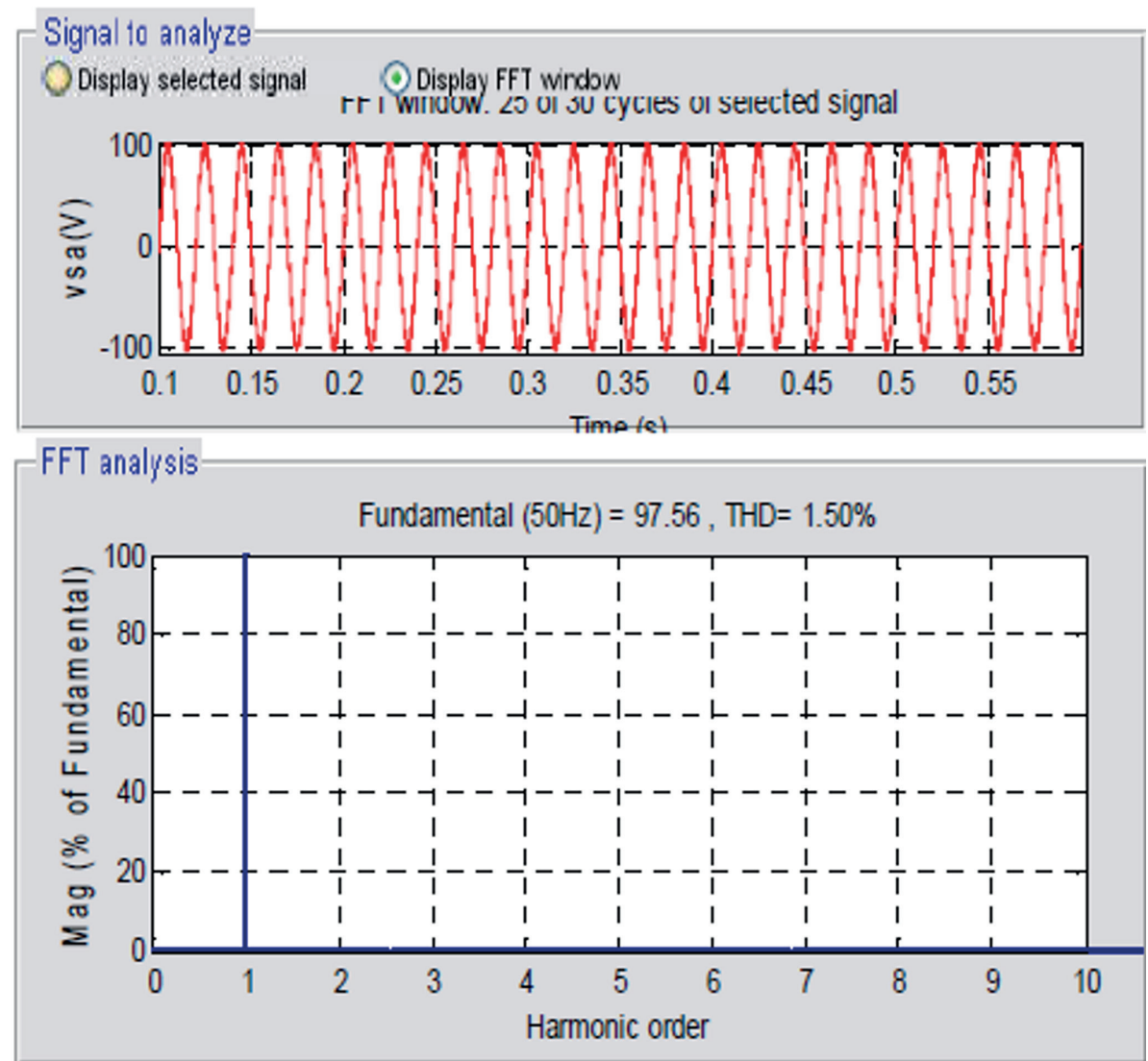

Fig. 21 Voltage Current source and its spectrum after installing SAPF 
In the rest of this section, we will see the feasibility of this strategy by simulation. For this test, the nonlinear load is modified following the variation of its resistance at the output of the rectifier bridge $P D_{3}\left(R L_{1}\right.$ to $\left.R L_{2}\right)$ at time $t=0.25 \mathrm{~s}$. Fig. 22 shows that the current call following this change is almost instantaneous $\Delta t=0.05 \mathrm{~s}$ without any distortion and good quality. But thus causing a decrease in the DC bus voltage during a transient of $\Delta t=0.08 \mathrm{~s}$ (Fig. 23). It should be noted that the DPC technique proves its robustness during this change and that by the excellent tracking of the active powers and reactive of their references (Fig. 24), with an injection of the same real power produced by the photovoltaic conversion chain. This injected power causes a power reduction provided by the three-phase grid (Fig. 25).

Fig. 26 shows the influence of changing the load on the waveforms of the PVG voltage, current and duty cycle. Note that the voltage and the current remain constant around their nominal values (operating point MPP) with a restricted range $(130 \mathrm{~V}-140 \mathrm{~V})$. This proves that the voltage of the PVG does not depend on the load variation. The variation will be in the value of the reference voltage of the DC bus according to the adaptation algorithm.

Fig. 27 illustrates the waveform of the source current and the evolution of the sectors as a function of time during the variation of the load.

After the commissioning of the SAPF we can notice that the source currents, after a transient of $t=0.01 \mathrm{~s}$ become sinusoidal with a THDi $=1.61 \%$ (Fig. 28 (a)), and are in phase with source voltages with THDv $=2.77 \%$ (Fig. 28 (b)). This control

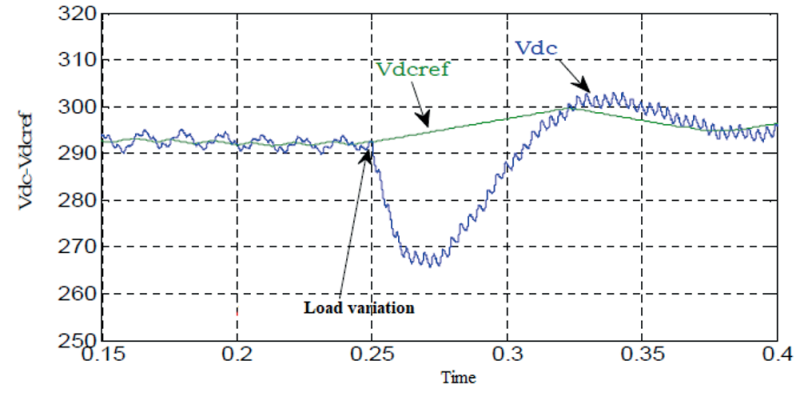

Fig. 23 DC bus voltage rate and its reference voltage when varying the nonlinear load (DPC)

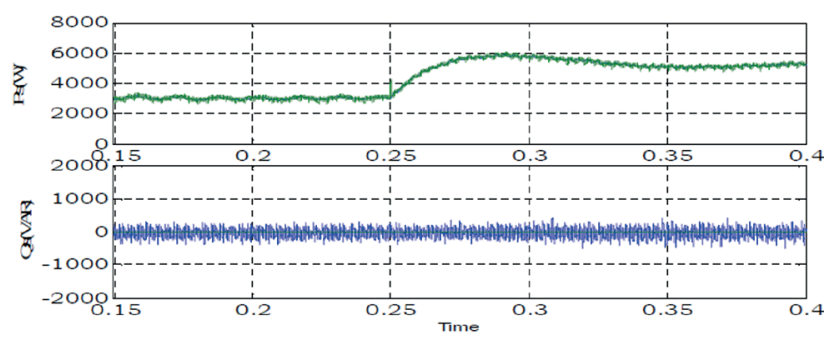

Fig. 24 Waveforms of instantaneous powers for a variation of the nonlinear load (DPC)

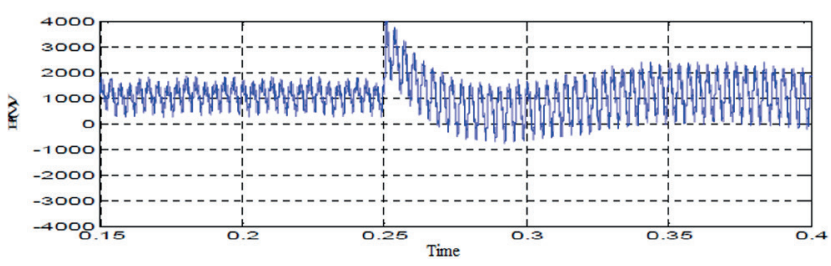

Fig. 25 Waveform of the active power injected into the grid when the load varies (DPC)

technique provides better energy quality compared to the previous technique.
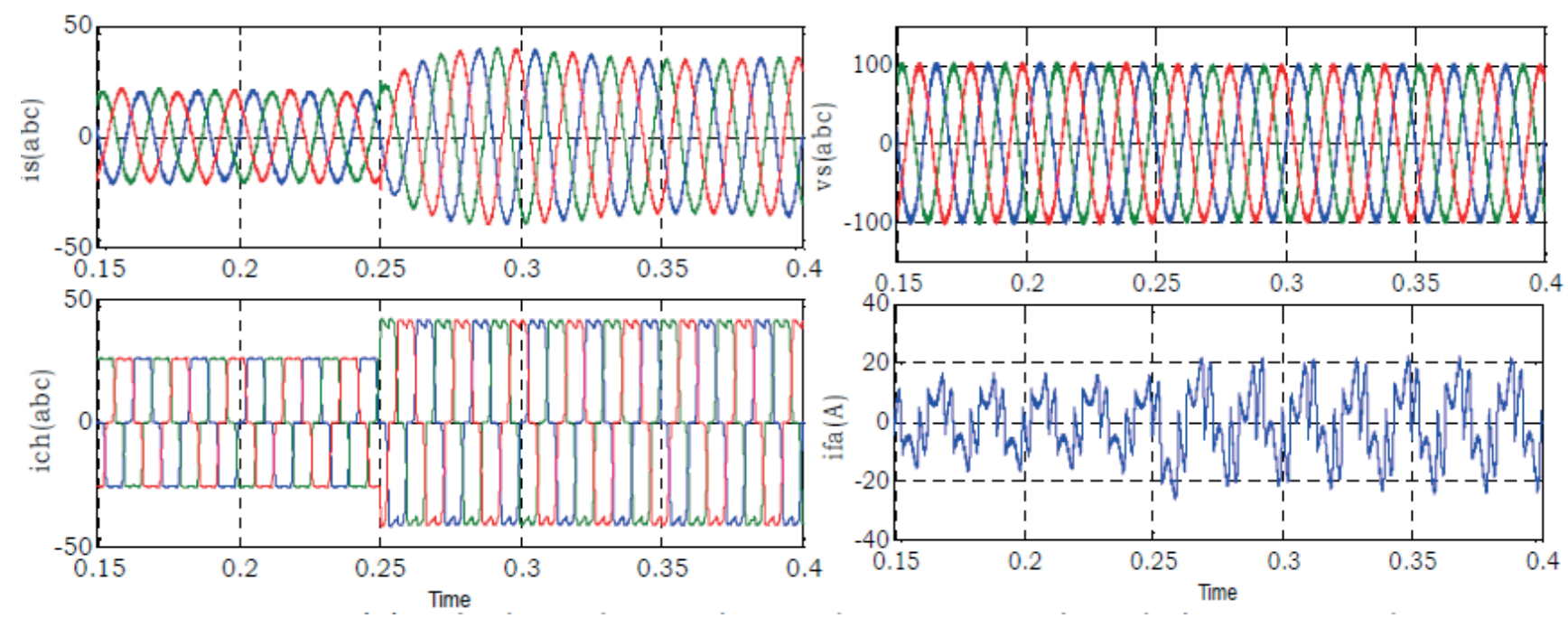

Fig. 22 Results of transient behavior when varying the load (DPC) 

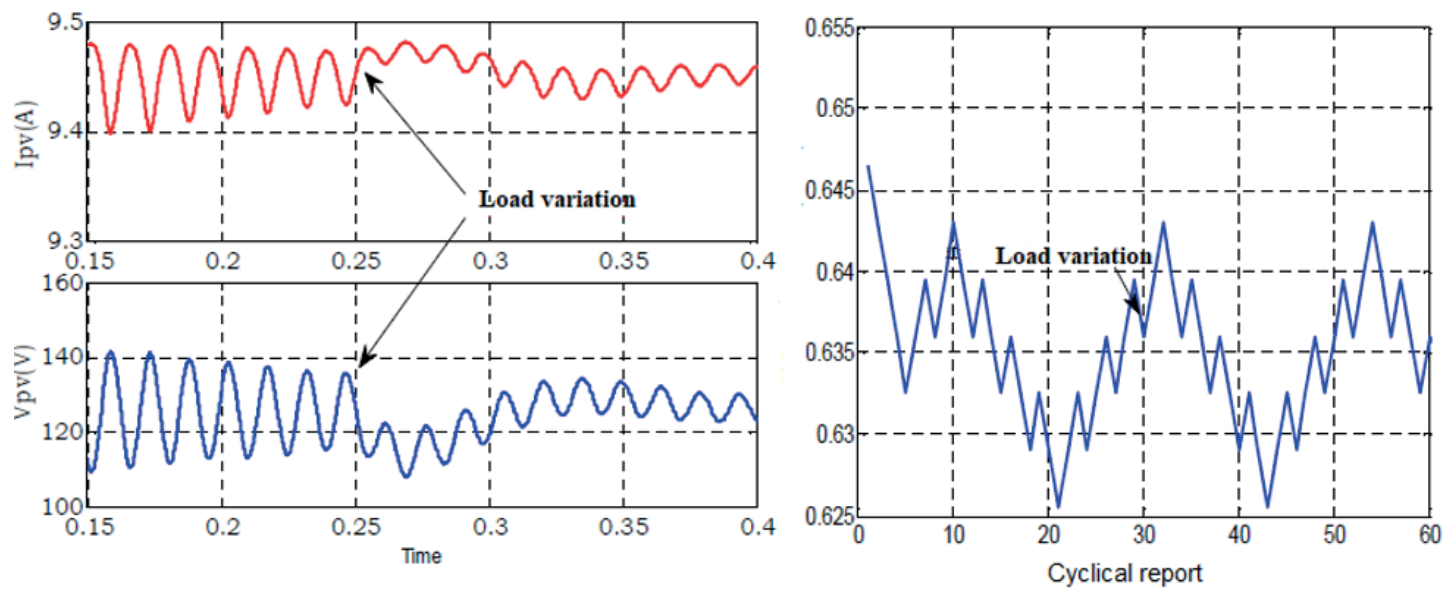

Fig. 26 Characteristic of the PVG according to the variation of the nonlinear load (DPC)

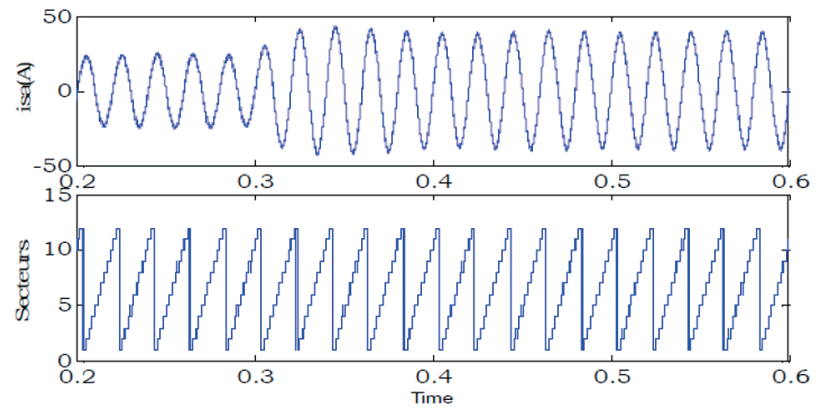

Fig. 27 Trends in the source current and the evolution of the sectors (DPC)
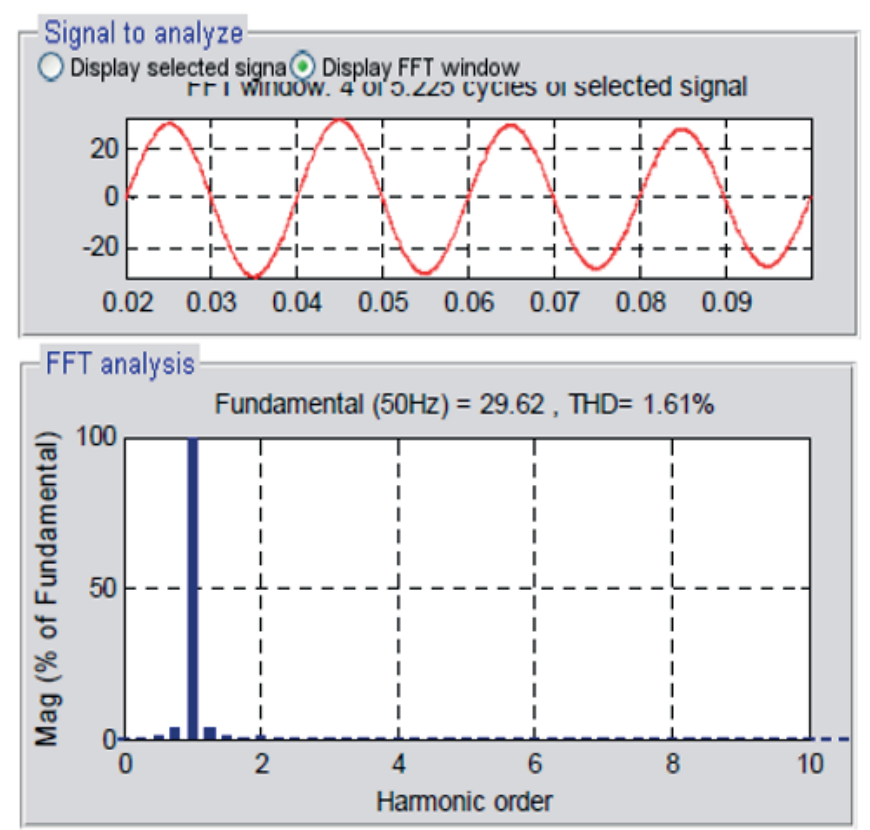

(a)
- Simulation of the general system with variable solar irradiation

As a result of this variation in the solar irradiation, a remarkable increase in the active power of the grid at time $t=0.2 \mathrm{~s}$, corresponding to $G a=50 \mathrm{~W} / \mathrm{m}^{2}$, and returns to its original value corresponding to $G a=1000 \mathrm{~W} / \mathrm{m}^{2}$ at instant $t=0.4 \mathrm{~s}$. This proves that there is a great power injected when the irradiation increases, and less power injected when it decreases, against the reactive power shows no change, remaining almost zero, to ensure good
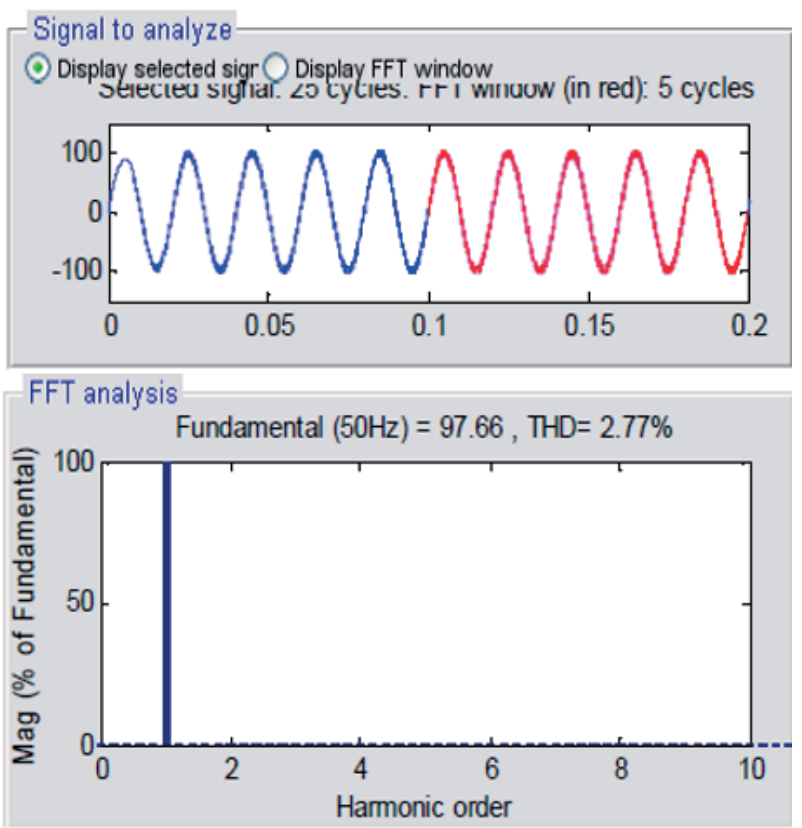

(b)

Fig. 28 Different spectra after SAPF commissioning: (a) source current, (b) source voltage (DPC) 
compensation of the reactive power. Regarding the DC bus voltage, it follows its reference during all ranges of variation, to ensure a good compensation of the reactive power. On the other hand, the THD is improved; THDi $=1.33 \%$ (Fig. 29), and the THDv $=1.8 \%$ (Fig. 30).

\section{Conclusion}

The study presented in this article concerns the modeling and control of a grid-connected photovoltaic system supplying a nonlinear load. The objective via the proposed control algorithms is to allow an optimal operation of the whole chain and this by two steps:

- Reduce the impact of the nonlinear load on the electricity network by eliminating current harmonics.

- Extract the maximum of the solar power, serving as a backup source to satisfy the load.

To achieve the first objective, two control strategies of the voltage inverter have been proposed: the Hysteresis Control and the DPC Control.

Both methods were simulated and evaluated in a comparative study based on the THD harmonic rate of the source current and the waviness at the power level. The results obtained demonstrate better performance of DPC. In the case of the Hysteresis Control of the SAPF, we observed a good quality of the signals in terms of Total Harmonic Distortion THDi $=2.51 \%$ (in the case of load variation) and $\mathrm{THDi}=3.32 \%$ (for the variation of solar irradiation) of the currents and voltages of the three-phase source. However, this current control technique induces at the spectrum level a wide frequency band due to the switching of the semiconductors, which is difficult to filter. While, in addition to the simplicity of the DPC control technique, a better control of the control of the active and reactive instantaneous powers is obtained. As well as a significant improvement of the current and voltage distortion rates compared to the Hysteresis Control strategy THDi $=1.61 \%$ for the case of load variation and $\mathrm{THDi}=1.33 \%$ for the variation of solar irradiation.

For the second objective and to maintain a constant voltage at the DC input of the inverter and avoid the regulation of this voltage because of the variations due to the losses in the active filter (switch and filter output), a GPV associated with a chopper boost was used. The latter controlled by the MPPT technique regulates the DC voltage around its reference value generated by an adaptation algorithm. The algorithm is based on the incremental conductance technique, the DC bus reference voltage which has proved its efficiency and offers better static and dynamic performance for the variation of load and solar irradiation.
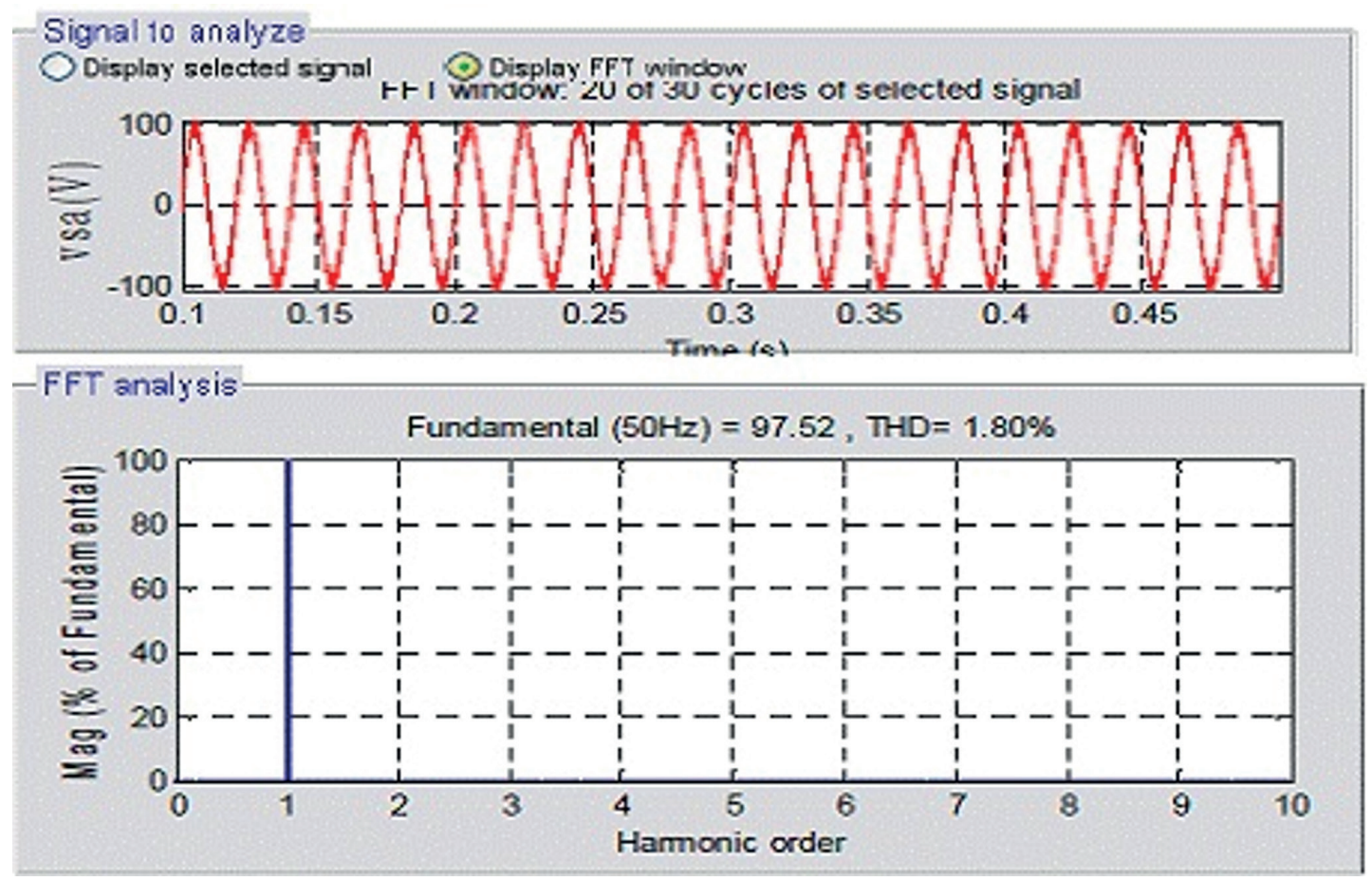

Fig. 29 Current source and its spectrum after installing SAPF (DPC) 

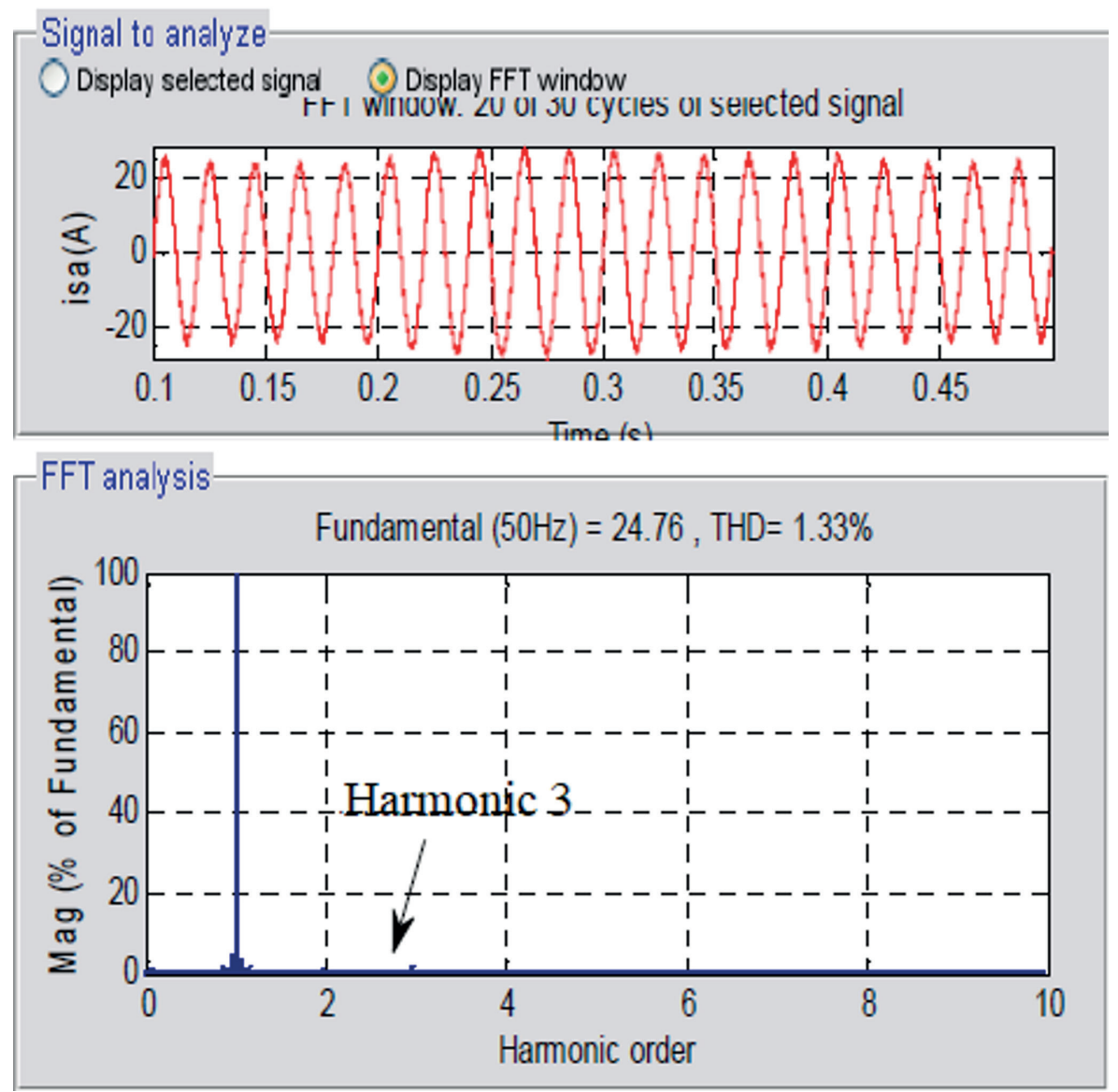

Fig. 30 Voltage source and its spectrum after installing SAPF (DPC)

\section{References}

[1] Pahari, O. P., Subudhi, B. "Integral sliding mode-improved adaptive MPPT control scheme for suppressing grid current harmonics for PV system", IET Renewable Power Generation, 12(16), pp. 1904-1914, 2018.

https://doi.org/10.1049/iet-rpg.2018.5215

[2] Abdel-Rahim, O., Funato, H. "An experimental investigation of modified predictive hysteresis control based MPPT strategy for PV applications", In: IEEE Energy Conversion Congress and Exposition (ECCE), Montreal, Quebec, Canada, 2015, pp. 6450-6454. https://doi.org/10.1109/ECCE.2015.7310563

[3] Abd Rahim, N., Selvaraj, J., Krismadinata "Hysteresis Current Control and Sensorless MPPT for Grid-Connected Photovoltaic Systems", In: IEEE International Symposium on Industrial Electronics, Vigo, Spain, 2007, pp. 572-577. https://doi.org/10.1109/ISIE.2007.4374659

[4] Aissa, O., Moulahoum, S., Colak, I., Babes, B., Kabache, N. "Analysis and experimental evaluation of shunt active power filter for power quality improvement based on predictive direct power control", Environmental Science and Pollution Research, 25(25), pp. 24548-24560, 2018.

https://doi.org/10.1007/s11356-017-0396-1

[5] Senguttuvan, S., Vijayakumar, M. "Solar Photovoltaic System Interfaced Shunt Active Power Filter for Enhancement of Power Quality in Three-Phase Distribution System", Journal of Circuits, Systems, and Computers, 27(11), article ID: 1850166, 2018. https://doi.org/10.1142/S0218126618501669
[6] Suja, K. R., Raglend, I. J. "Adaptive Genetic Algorithm / NeuroFuzzy Logic Controller Based Unified Power Quality Conditioner Controller for Compensating Power Quality Problems", Australian Journal of Electrical and Electronics Engineering, 10(3), pp. 351-361, 2013.

https://doi.org/10.7158/1448837X.2013.11464384

[7] Xu, B., Yang, D., Jiao, J. "Coordinated Control Strategy Based on DPC-SVM-DTC Three-Level Dual PWM Converter", International Journal of Control and Automation, 10(2), pp. 327-338, 2017. https://doi.org/10.14257/ijca.2017.10.2.27

[8] Koad, R. B. A., Zobaa, A. F., El-Shahat, A. "A Novel MPPT Algorithm Based on Particle Swarm Optimization for Photovoltaic Systems", IEEE Transactions on Sustainable Energy, 8(2), pp. 468-476, 2017. https://doi.org/10.1109/TSTE.2016.2606421

[9] Chelli, Z., Toufouti, R., Omeiri, A., Saad, S. "Hysteresis Control for Shunt Active Power Filter under Unbalanced Three-Phase Load Conditions", Journal of Electrical and Computer Engineering, article ID: 391040, 2015. https://doi.org/10.1155/2015/391040

[10] Gururaj, Anguraja, R., Prakash, R., Naganagouda, H. "Comprehensive Approach of Modeling and Simulation of Solar Photovoltaic Power Plant", International Journal of Engineering Research and Applications, 7(7), pp. 6-11, 2017. https://doi.org/10.9790/9622-0707030611 
[11] Menon, M. K. D. "A novel method to extract maximum power from solar panel of a grid connected phototvoltaic system using phase angle control and hysteresis current control", In: International Conference on Electrical, Electronics, and Optimization Techniques (ICEEOT), Chennai, India, 2016, pp. 3510-3516. https://doi.org/10.1109/ICEEOT.2016.7755357

[12] Chaoui, A., Krim, F., Gaubert, J.-P., Rambault, L. "DPC controlled three-phase active filter for power quality improvement", International Journal of Electrical Power and Energy Systems, 30(8), pp. 476-485, 2008.

https://doi.org/10.1016/j.ijepes.2008.04.009
[13] Adamidis, G., Tsengenes, G., Kelesidis, K. "Three Phase Grid Connected Photovoltaic System with Active and Reactive Power Control Using "Instantaneous Reactive Power Theory"', Renewable Energy and Power Quality Journal, 1(8), pp. 1086-1091, 2010. https://doi.org/10.24084/repqj08.591 